\title{
Sobre lo aparente y lo real: respuesta a Néstor L. Cordero y a Jorge Mittelmann
}

\author{
MARCELO D. BOERI \\ Instituto de Filosofía \\ Universidad de los Andes \\ mboeri@uandes.cl
}

\begin{abstract}
Resumen: Ésta es la réplica a las objeciones de Cordero y Mittelmann a mi libro Apariencia y realidad en el pensamiento griego. En la respuesta principal a Cordero muestro que, incluso en el Sofista, donde parece explotarse mayormente el aspecto proposicional del conocimiento, Platón mismo sugiere la idea del conocimiento en sentido disposicional. A las objeciones de Mittelmann argumento (i) que, aunque Aristóteles no usa habitualmente la palabra "criterio", eso no significa que carezca del concepto. En respuesta a la objeción se sugiere (ii) que, como lo indica el texto aristotélico en el que baso mi tesis (De insomniis 460b3-4), Aristóteles no está considerando el caso de la percepción de los sensibles propios, que está libre de error o admite un error mínimo (De anima 428b18-19), sino, probablemente, el de la percepción en su sentido transensorial.
\end{abstract}

Palabras clave: Platón, Aristóteles, conocimiento, error

\begin{abstract}
This is the reply to Cordero's and Mittelmann's objections to my book Apariencia y realidad en el pensamiento griego. In my main reply to Cordero I show that, even in the Sophist, where the propositional aspect of knowledge is mostly emphasized, Plato himself suggests the idea of knowledge in the dispositionsal sense. I reply to Mittelmann's objections that (i), even though Aristotle does not use the word "criterion", this does not mean that he lacks the concept. In my reply to objection (ii) I suggest that, as is pointed out by the Aristotelian text on which my thesis is based (De insomniis 460b3-4), Aristotle is not considering the perception of proper sensibles, which is free of error or admits the least possible amount of error (De anima 428b18-19), but the perception in its transensorial sense.
\end{abstract}

Key words: Plato, Aristotle, knowledge, error

\section{Respuesta a Néstor Luis Cordero}

Habitualmente, una réplica presupone responder a algún aspecto crítico que alguien ha hecho a una interpretación o a un argumento. En realidad, no tengo mucho que "replicar" en ese sentido, pues no sólo el profesor Néstor L. Cordero ha tenido la amabilidad de comentar — con mucha generosidad en sus apreciaciones- los primeros capítulos consagrados a Platón de mi libro Apariencia y realidad en el pensamiento griego $(A R)$, sino que además sus observaciones parecen coincidir con varias de mis sugerencias y enfoques. Eso, claro está, no tiene nada de 
malo: cuando un experto en Platón como Cordero hace afirmaciones tan positivas sobre el propio trabajo, uno incluso puede estar tentado a creer que va por el buen camino.

Aunque en general Cordero parece coincidir con el enfoque de mi libro (en su caso, el dedicado a Platón), hay dos aspectos que parecen generarle dudas: (i) lo que él llama mi "provocación", y (ii) lo que considera una "abusiva presencia" del diálogo Teeteto en los capítulos dedicados al socratismo y a Platón. En lo que sigue me centraré en estos dos detalles con el propósito de aclarar mi enfoque y de dar una respuesta a la objeción de presunta provocación de mi parte y a la abusiva presencia del Teeteto en mi libro (en los capítulos 3-4). Comencemos por el punto (i) y los ingredientes de "provocación" que contendría $A R$. Según Cordero, parece que yo pretendo "debilitar, e incluso suprimir, el tan criticado $\chi$ wplouós". Como se ve enseguida, Cordero muestra que mi aparente intención de eliminar la separación está conectada de modo directo con su segundo reproche: (ii) haber hecho un uso abusivo del Teeteto y un uso extremadamente restringido del Sofista que, en su opinión, me habría dado algunos elementos de peso para justificar mi posición. Eso es así, sugiere Cordero, porque el notable pasaje de Sofista 247e relativiza cualquier noción de separación en la medida en que allí lo individual-sensible es "realmente real" (una descripción habitual de las Formas en Platón: República 490b5, 597d1-2; Fedro 247c7-e3, 249c4; Timeo 28a3-4). En efecto, en el Sofista Platón establece fuera de toda duda que todo lo que posee el poder o capacidad de actuar o de

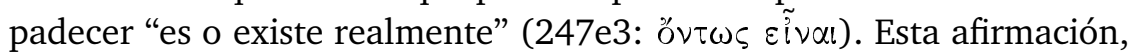
llevada al dominio de la discusión epistemológica y, sobre todo, moral, puede significar que los particulares sensibles pueden ser conocidos o que los casos particulares de acción y, por ende, el bien involucrado en ellos "son o existen realmente".

En cierto modo, es notable lo que un texto propio puede generar en la lectura de otro, pues de hecho nunca me propuse dsatar una polémica respecto del complejísimo problema de la separación en Platón ni introducir un elemento "provocador" al respecto, aunque sin duda trabajé con el supuesto de que la "metafísica de los dos mundos" requiere siempre un esfuerzo por superar la lectura superficial que asume que, de ser cierta, no hay en Platón una conexión real entre ambos dominios. El hecho mismo de que Platón sugiera que hay una "presencia" ( $\pi \alpha p o v \sigma i \alpha)$ de las Formas en los particulares sensibles que las ejemplifican (cfr. Fedón 100d; véase también Sofista 247a) habla en contra de semejante interpretación trivial. No obstante, aunque tuve la tentación de hacer una discusión más o menos detallada de la noción de 
"separación" y el modo en que eventualmente se aplicaría tal noción a los aspectos de teoría de la acción y ética platónica que discuto en mi libro, preferí no hacerlo para evitar introducir dificultades mayores. Sin embargo, no pude evitar ofrecer, al menos de una manera general, una interpretación de cómo entender el problema de la separación y, en particular, el modo en que estaría conectada la Forma del Bien con la acción particular y, obviamente, en especial, con la acción buena. Como es evidente, mi intento solapado de discutir ese difícil problema no pasó inadvertido al profesor Cordero, y su objeción me da la oportunidad de aclarar el tema un poco mejor.

Es cierto que el pasaje del Sofista citado por Cordero me habría dado un mejor fundamento para justificar mi posición; pero no es menos cierto que es ya en la República, uno de los diálogos en los que se plantea la "metafísica de los dos mundos", donde Platón establece con toda claridad que, a pesar del carácter paradigmático de las Formas y de su característica privilegiada de unidades absolutas, hay una manera de hacer "reales" (en el sentido de hacer bajar al dominio sensible del cambio) las Formas. Como intento mostrar en el capítulo 2 de $A R$, es Platón mismo quien exige la necesidad de conocer el Bien para ser también capaz de conocer algo bueno (cfr. República 534b-c y AR, p. 63). Ésta era mi explicación en $A R$ (siguiendo el texto platónico) de por qué el régimen político adecuado podrá ser realizado, en la medida de lo posible, si hubiese algún guardián capaz de conocer en qué sentido las cosas bellas y justas son "buenas" (República 506a-b, 517c, y AR, p. 80). Aunque Platón nunca dice que uno puede alcanzar una Forma sin más (en cuanto a que la misma sea "realizable" en sentido estricto, como exigía Aristóteles), sí argumenta que las Formas son alcanzables en la medida en que uno llega lo más cerca posible a ellas (República 472bd): la Forma, en efecto, no puede llevarse a la práctica en los mismos términos en que se la enuncia en el discurso (cfr. $A R$, pp. 80-81). Éste era mi argumento y mi sugerencia de por qué Platón parece "neutralizar", por así decir, el problema de la separación en su consideración de la relevancia de la Forma del Bien en el dominio práctico. Mi objetivo era, más que una provocación, mostrar que es Platón mismo quien previene respecto de la interpretación trivial del tema de la separación.

Para concluir la respuesta al profesor Cordero, me permito hacer una breve explicación respecto del "uso abusivo" del Teeteto (en particular en los capítulos 3-4 de $A R$ ). No hay duda de que he hecho el uso que denuncia Cordero de ese diálogo; si tuviera que explicarlo, diría que en parte el contexto del capítulo 3 (donde discuto el problema de apariencia y realidad en la epistemología platónica) y del 4 (donde propongo 
hacer una lectura "disposicional" de la epistemología platónica) así lo requerían, y en parte porque, como traté de argumentar en ese contexto, el Teeteto es, casi como ningún otro diálogo de la producción platónica, un texto muy peculiar que resultaba muy útil a los fines de lo que me proponía mostrar: en efecto, no sólo presenta una discusión concentrada sobre el problema del saber o conocimiento ( $\dot{\varepsilon} \pi \sigma \tau \eta \dot{\eta} \mu \eta$ ), sino que además ofrece algunas pistas sugerentes en dirección de la interpretación y tesis central del capítulo, esto es, que Platón está más interesado en enfatizar el aspecto disposicional (o "actitudinal") del saber que el proposicional, de modo que el estado psicológico o anímico del agente puede ser decisivo en el continuo proceso de búsqueda del saber ( $c f r . A R$, pp. 130 ss.). Una parte importante de mi argumento era mostrar que, además de la relevancia que pueden tener los ingredientes disposicionales, la ignorancia de la que habla Platón en el Teeteto (y en otros diálogos) no es básicamente ignorancia de ciertos contenidos cognitivos definidos (como la de quien se dice que es ignorante porque no conoce un hecho histórico o las operaciones matemáticas básicas), sino más bien el estado anímico de creer saber lo que en realidad no se sabe. En esta línea argumentativa -y esto sí fue una provocación de mi parte-, hacia el final del capítulo 4 cito dos significativos pasajes del Sofista, el diálogo en que Platón parece explotar mayormente el aspecto proposicional del conocimiento: en el primer pasaje del Sofista que cito (229c1-5), el visitante concluye que es un enorme y difícil tipo de ignorancia creer que uno sabe, aunque en realidad no sepa ( $\tau$ ò $\mu \grave{r}$ $x \alpha \tau \varepsilon l \delta o ́ \tau \alpha \tau$ que el alma no puede aprovechar los conocimientos que recibe hasta que uno, luego de ser refutado, elimina las opiniones que intervienen en el aprendizaje y se encuentra "creyendo que conoce aquellas cosas que solamente conoce y nada más [...]. Éste es el mejor y más sabio

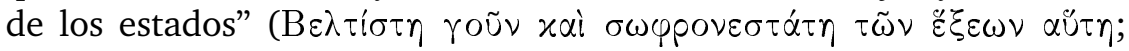
Sofista 230d1-5; cfr. AR, p. 136). Es decir, incluso en un contexto en el que Platón enfatiza el enfoque proposicional del saber, no parece estar dispuesto a abandonar los ingredientes disposicionales.

Si esta justificación de mi uso abusivo del Teeteto es al menos razonable, ahora podría preguntarse cuál es el significado de la introducción del aspecto disposicional del saber en el Sofista, el diálogo en el que Platón parece privilegiar el tratamiento proposicional del saber. Ése seguramente será tema de un nuevo apartado de mi capítulo 4 de $A R$ en caso de que tenga oportunidad de revisar ese texto en el futuro. Si ése efectivamente fuera el caso, estaré en deuda con Cordero por urgirme a dar estas explicaciones. 


\section{Respuesta a Jorge Mittelmann}

En su comentario a $A R$, Jorge Mittelmann hace notar, correctamente a mi juicio, mi referencia y, en cierto modo, enfática insistencia sobre la presencia de modos de discriminar entre dos apariencias en conflicto en Aristóteles. Además de eso, presenta dos objeciones: (i) aunque sostengo que Aristóteles puede haber visualizado un criterio para distinguir apariencia de realidad, nunca hago explícito cuál es tal criterio de rectitud en nuestras discriminaciones perceptivas (el reproche se repite en la sección conclusiva de su nota a mi interpretación general de la psicología y de la psicología moral aristotélicas). En segundo lugar, Mittelmann, apoyándose en una observación de J. Barnes, también me objeta (ii) que no estoy autorizado a generalizar las consecuencias anómalas de ciertos estados pasionales sobre las percepciones porque el error afecta a objetos incidentales de percepción y es respecto de ellos que las pasiones inducen más fácilmente a error. Dado que ambos reproches son razonables, me parece que debo intentar responder a ellos. La respuesta más directa a (i) y, en cierta manera, ingenua que se me ocurre es que, aunque es posible conjeturar la existencia de ese criterio, no hay modo de individualizarlo con claridad toda vez que Aristóteles tampoco lo hace de modo explícito. Pero este tipo de respuesta seguramente no alcanza para cubrir las expectativas del profesor Mittelmann y, probablemente, las de ningún lector atento de esta nota, de mi libro o, lo que es más importante, de los textos aristotélicos. Respecto de la objeción (ii), que es más de fondo, ni siquiera se me ocurre ofrecer una respuesta ingenua pues, de ser cierta, una parte importante de mi argumento anclado en el poder desintegrador de las pasiones como factores que irremediablemente obnubilan la correcta distinción entre apariencia y realidad podría desmoronarse. En lo que sigue me propongo realizar un esfuerzo por hacer explícito el criterio que anunciaba, aparentemente de modo enigmático, en mi libro ( $c f r . A R$, p. 230) para responder a la objeción (i); en un segundo momento presentaré un argumento textual y otro sistemático-conceptual para mostrar que puede mantenerse razonablemente la idea de que los estados emocionales o pasionales son una fuente importante de error (si no absoluta, al menos muy poderosa). En mi intento de responder a (i) y (ii) también procuraré hacer algunas precisiones respecto de lo que Mittelmann elegantemente llama mi "genealogía moral del error perceptivo" y otros puntos de detalle, para aclarar algunos aspectos de mi interpretación.

(i) Según Mittelmann, mi supuesto básico es que la distinción entre lo aparente y lo real no es "estrechamente" epistémica; puesta en su 
contexto, esa observación significa que yo sostengo que los contextos en los que originariamente surge la distinción apariencia-realidad en Aristóteles son de tipo fundamentalmente práctico, lo cual probablemente significa que no se trata de dominios en los cuales el aspecto senso-perceptivo sea el decisivo. Hay un sentido en el que esa observación es correcta y otro en la que no lo es: es correcta en la medida en que sin duda he enfatizado con particular vigor la relevancia de la distinción en contextos prácticos, mostrando así que la distinción no se encuentra exclusivamente anclada del lado "epistémico-cognitivo", por así decir. En efecto, como hago notar en el capítulo 5 de $A R$ (p. 149), Aristóteles parece haber incorporado sin discusión la tesis socráticoplatónica de que una cosa es "lo que parece bueno" y otra "lo que es bueno", desafiando de esta manera la identificación entre "aparecer" y "ser" propia del enfoque protagórico. Hay, por otro lado, un sentido en que la observación no es correcta, porque, como he hecho notar en ese mismo capítulo, la tesis que subyace a esa distinción en el dominio práctico es que el procedimiento de búsqueda es precedido por un momento cognitivo-perceptivo. Si esto es así, el problema debería ser visto probablemente como un fenómeno en el cual el momento perceptivoepistémico es al menos condición necesaria de la distinción aparienciarealidad en el nivel práctico, ya que el modo en el que un humano se relaciona con el mundo es, al menos en un primer momento, por vía senso-perceptiva. En este punto de detalle Aristóteles parece seguir a Platón o inspirarse en él. ${ }^{1}$

${ }^{1}$ Cfr. Platón, Teeteto 186b-c y Aristóteles, Analíticos posteriores 100a3-b5, donde enfatiza no sólo que la sensación ( $\alpha \imath \vartheta \vartheta \eta \sigma \iota \varsigma)$ es condición necesaria de procesos y estados cognitivos como memoria, experiencia, arte y ciencia, sino también que la

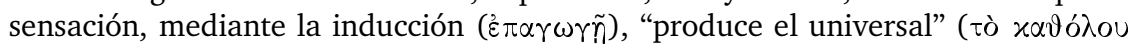
$\varepsilon \jmath \mu \pi 0 เ \varepsilon \tilde{i} ;$ 100b5). Véase también 99b35, donde la sensación es definida como "una facultad connatural o innata capaz de discriminar o distinguir", y De sensu 447b2526. Para la discusión platónica del sensismo epistemológico cfr. Teeteto 152b-c; la posición sensista (que identifica conocimiento con sensación y que procede mediante la identificación de "ser" y "aparecer") tendría, en opinión de Platón, la negativa consecuencia de un relativismo moral y político que anularía el criterio para distinguir lo que es justo de lo que no lo es (para una discusión pormenorizada de este tema me permito remitir a Boeri 2007). En su interpretación de la tesis protagórica del homo mensura, Platón sostiene que para los protagóricos ese "criterio"

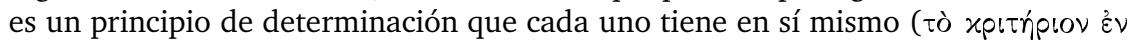

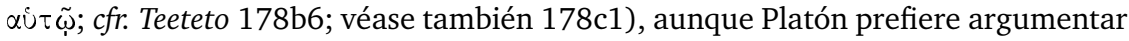
a favor de la tesis de que un criterio más confiable (y menos subjetivamente psicológico) es la experiencia, el conocimiento y el argumento (cfr. República 582a; en Leyes $767 \mathrm{~b}$ aparece xpıtńpı $\alpha$, pero allí no tiene valor epistemológico, sino judicial).

Diánoia, vol. LIV, no. 63 (noviembre 2009). 
Por otra parte, es cierto que en Aristóteles no es habitual la palabra "criterio" (xpırńpıv), aunque el hecho de que no tenga la palabra o, más precisamente, que no la use de modo habitual, no significa que carezca del concepto. ${ }^{2}$ Es más, aunque no habla normalmente de "criterio de verdad" (teórico o práctico), dice con cierta frecuencia que la senso-percepción es un "criterio" o posee una capacidad de discriminar. ${ }^{3}$ Pero hay otro detalle relevante que hay que tener en cuenta en la búsqueda de este "misterioso" criterio que propongo en $A R$ : si lo que he estado sugiriendo hasta el momento es plausible, uno tendría que sospechar que ese "criterio" que Aristóteles habría visualizado para dis-

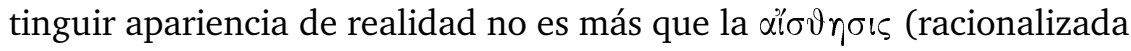

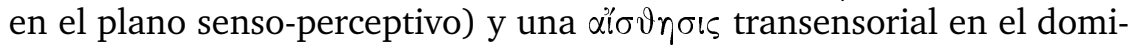
nio práctico. Eso es, precisamente, lo que argumenté en $A R$ (p. 250) al discutir el problema de la $\varphi \alpha \nu \tau \alpha \sigma i \alpha$ racional o deliberativa que, como toda $\varphi \alpha \nu \tau \alpha \sigma i \alpha$, en algún momento debe haber sido $\alpha i \sigma \vartheta \eta \sigma \iota s$, aunque no sensación en el sentido de la pura sensibilidad, sino en el que tiene la palabra en el pasaje de Política 1253a16-18: como "captación" de ciertas nociones prácticas (bueno, malo, justo, injusto) que luego, cuando esa percepción no está presente, podremos representarnos de modo de ser capaces de planear nuestra vida práctica. Así, pues, si se extiende la analogía, podría conjeturarse que tal como el sentido ("sensible") es capaz de distinguir tipos de cualidades sensibles, el sentido ("transensorial") debe ser capaz de distinguir tipos de conceptos evaluativos, una distinción relevante al momento de discriminar el bien aparente del bien real. ${ }^{4}$ La posibilidad de hacer una extensión de la senso-percepción al dominio práctico ya está sugerida por el mismo Aristóteles no sólo en el pasaje de la Política recién citado, sino también en Ética nicomáquea,

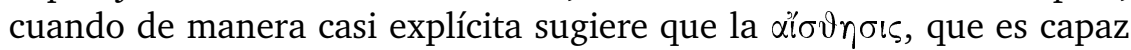
de percibir nociones evaluativas, no es un conocimiento sensible, sino

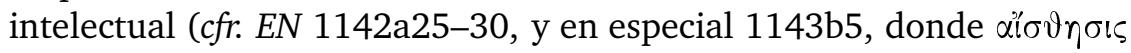

2 En realidad, Aristóteles usa al menos una vez la palabra "criterio" (cfr. Metafísica 1063a3), aunque allí no lo hace en el sentido fuerte de "criterio" (presumiblemente de verdad), sino como atributo de "órgano sensorio, que discierne o discrimina".

${ }^{3}$ Cfr. de nuevo Analíticos posteriores $99 \mathrm{~b} 35$ y De anima 422a21 (donde la vista discierne); 424a5 (la sensación discierne los sensibles); 425b21 (donde sostiene que "discernimos mediante la vista no sólo la oscuridad sino también la luz"); 426b9-10 (donde cada sentido discierne las diferencias sensibles), et passim.

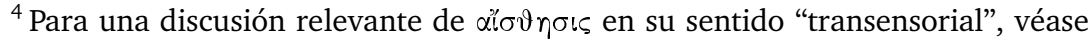

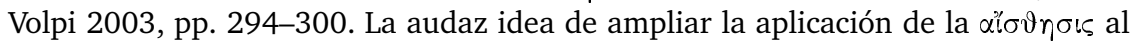
dominio práctico es original de Welsch 1987, a quien Volpi sigue. 


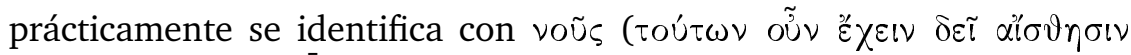

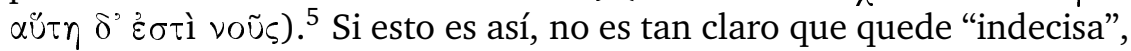
como cree Mittelmann, mi formulación respecto de si las apariencias contrapuestas entre las que el agente discrimina pertenecen al ámbito

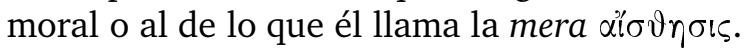

(ii) La segunda objeción de Mittelmann se concentra en el poder, excesivo en su opinión, que atribuyo a los estados emocionales como factores que causan engaño a nuestras senso-percepciones. Cuando yo afirmo que "cuando somos afectados por nuestras pasiones o estados afectivo-emocionales somos fácilmente engañados en lo que respecta a nuestras senso-percepciones" (AR, pp. 232-233), Mittelmann parece sugerir que no a todas. En efecto, si la experiencia perceptiva de los sensibles propios no es particularmente vulnerable a los influjos emotivopasionales, no parece correcto sostener, como hago yo, que cuando nos encontramos en estados pasionales somos fácilmente engañados en lo que respecta a nuestras senso-percepciones. Touché, es una buena objeción: uno podría estar en un estado de enojo severo, por ejemplo, pero seguir viendo lo que es visible u oyendo lo que es audible, sin que esa experiencia perceptiva constituya un error o engaño, y mostrar así que no es cierto que un estado emocional tenga un poder causal que induzca a engaño en el plano perceptivo.

Se me ocurre, sin embargo, ensayar la siguiente respuesta: si mi én-

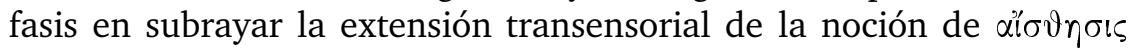
operada por el mismo Aristóteles es apropiado, creo que hay una manera muy razonable de evadir la objeción. Las emociones o pasiones

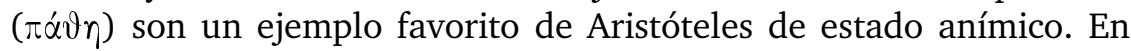
efecto, constituyen el ejemplo perfecto para mostrar que, aunque el alma no es un cuerpo, no se da si no es a través del cuerpo (De anima 414a19-20), ${ }^{6}$ razón por la cual se explica el carácter "anfibio" de los estados afectivos o emocionales y de su caracterización como $\lambda$ ó

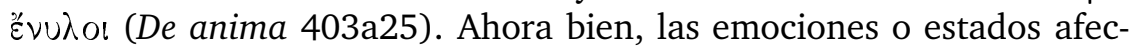
tivos, según Aristóteles, no sólo afectan el juicio, sino que, según sea el juicio o la propia creencia del sujeto, así será también su estado emocional (discuto esta tesis aristotélica en $A R$, pp. 256-262). Si la

\footnotetext{
${ }^{5}$ Naturalmente, Aristóteles no quiere decir que la sensación y el intelecto sean exactamente lo mismo, sino que lo que los hace semejantes es el hecho de que ambas facultades cognitivas captan lo que captan de modo directo, sin que haya mediación. El pasaje citado, sin embargo, puede plantear la posibilidad de que ambas facultades sean capaces de captar nociones evaluativas.

${ }^{6}$ Para este importantísimo, en mi opinión, dictum de la psicología aristotélica me permito enviar a Boeri 2009.
} 
objeción (ii) de Mittelmann es plausible, yo debería debilitar mi afirmación y reformularla diciendo "cuando somos afectados por nuestras pasiones o estados afectivo-emocionales somos fácilmente engañados en lo que respecta a ciertas senso-percepciones". El problema es que lo que dice Aristóteles en De insomniis 460b3-4 (que es el texto en que se basaba mi afirmación) es que "cuando nos encontramos sumidos en

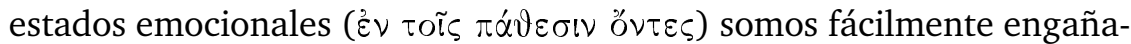

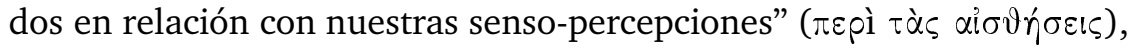
no que lo somos en relación con ciertas senso-percepciones o en ciertos casos de percepción. Esto me hace pensar que, tal vez, Aristóteles no está contemplando aquí el caso de la senso-percepción de los sensibles propios, que están libres de error o implican un error mínimo (De anima 428b18-19), sino, probablemente, el de la senso-percepción en su sentido transensorial. El estado emocional de miedo, por ejemplo, se produce porque el sujeto cree que lo que se aproxima es malo para él (ésta es la etiología de los estados afectivo-emocionales según Retórica II; discuto el punto en $A R$, capítulo 7), de donde parece seguirse que "percibe" algo como temible, aunque no lo sea (eso debe significar que "somos engañados en nuestras senso-percepciones"). Pero esa percep-

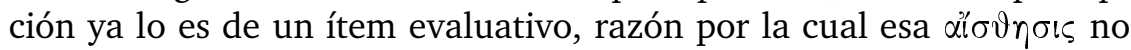
puede ser puramente sensible. Si este argumento es razonable, no sería extraño que Aristóteles piense que las senso-percepciones vinculadas a estados emocionales como el miedo o el amor (los ejemplos dados en De insomniis 460b5; cito el pasaje en $A R$, p. 233) tengan la capacidad de percibir algún tipo de ingrediente evaluativo (como la percepción de lo malo de la que habla Aristóteles en el pasaje de la Política antes citado).

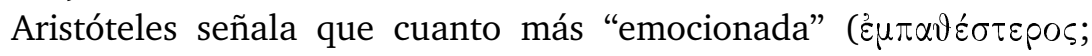
460b7-8) se encuentre la persona, una semejanza tanto menor se requerirá. ${ }^{7}$ De lo cual infiere que también en los estados de iracundia o en todos los estados que involucren deseos apetitivos (debe estar pensando en los deseos sexuales, de comida o de bebida) todas las personas

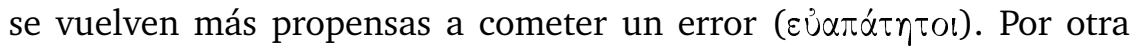
parte, a partir de esta afirmación uno podría pensar que Aristóteles

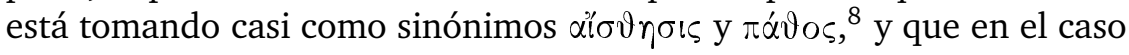

${ }^{7}$ Se refiere al hecho de que cualquier cosa parecida al miedo inspira algo temible al miedoso, quien ve enemigos por todas partes, o la semejanza al objeto de amor inclina al enamorado a ver a lo que es objeto de su amor en cualquiera (De insomniis 460b6-7).

${ }^{8}$ En cuyo caso aquí diø $\vartheta \eta \sigma \iota s$ no podría entenderse en su sentido transensorial,

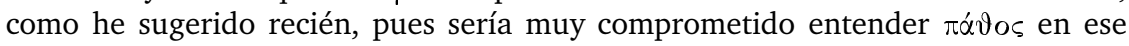


de $\pi \dot{u} \vartheta o \varsigma$ su significado oscila entre "estado emocional" (ira, miedo, amor, apetitos) y el significado más general de "estado afectivo". ${ }^{9}$ Pero si esto es así, cuando Aristóteles dice que si nos encontramos sumidos en estados emocionales somos fácilmente engañados en relación con nuestras $\alpha i \sigma \vartheta \hat{\gamma} \sigma \varepsilon ı \varsigma$ no puede estar pensando en la experiencia de los sensibles propios, como argumenta Mittelmann, que no son igualmente vulnerables a la influencia disociadora de los estados emotivo-afectivos intensos (como argumenta Aristóteles en De anima 429a4-8 — citado

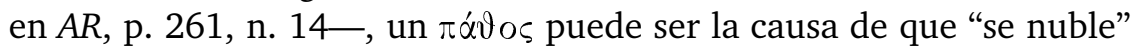
el intelecto).

Aunque todavía tengo ciertas dudas sobre una de mis respuestas a la objeción (ii), esto es, que en el pasaje de De insomniis di̋ valor transensorial, creo que he dado razones para poner en duda que en el texto en cuestión Aristóteles esté pensando en los sensibles propios y en la situación de invulnerabilidad en que éstos se encontrarían respecto del influjo de los estados afectivo-emocionales. Es probable que mi objetor no esté completamente satisfecho con mi respuesta; seguramente lo más sensato es seguir pensando el tema. Pero la discusión dialógica que he mantenido con Jorge Mittelmann en este texto (y en conversaciones personales durante los últimos tres años) me ha permitido reparar en esos dos detalles que, tal vez, no estaban del todo claros en mi libro. ${ }^{10}$

sentido, además del hecho que no hay evidencia textual para pensar que pueda tener algún significado evaluativo, como sí la hay para di̊

${ }^{9}$ Esto explica que ponga el ejemplo de los que tienen fiebre, a quienes se les aparecen animales que caminan por las paredes; hay casos, observa Aristóteles, en los que, a pesar de que el estado afectivo de enfermedad es muy intenso, al sujeto no le pasa inadvertido que es falso el estado de cosas producido por sus alucinacio-

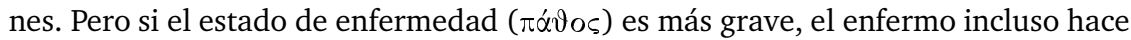
movimientos que se ajustan a los supuestos animales que cree ver, en cuyo caso el juicio ya se ve modificado por su estado afectivo. Lo que quiere enfatizar Aristóteles es que la capacidad de juzgar es diferente de la producir imágenes (De insomniis 460b11-18), aunque es cierto que ciertas imágenes son capaces de producir errores de juicio cuando el sujeto se encuentra en un particular estado afectivo que nubla su intelecto.

10 Deseo expresar mi sincero agradecimiento a Néstor Cordero y a Jorge Mittelmann por su buena disposición y diálogo crítico. También quiero agradecer a Ricardo Salles, director de Diánoia, y al Comité de Dirección por aceptar esta discusión. 


\section{BIBLIOGRAFÍA}

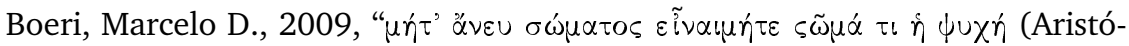
teles, De anima B 2. 414 a 19-20). A propósito del alcance de las interpretaciones funcionalistas de la psicología aristotélica y del carácter causal del alma", Elenchos. Rivista di studi sul pensiero antico, vol. 30, no. 1, en prensa. — 2007, "Percepción y estados afectivos en Platón", Quaderni Urbinati di Cultura Classica, vol. 87, no. 2, pp. 71-93.

Volpi, Franco, 2003, "Das Problem der Aisthesis bei Aristoteles”, en G. Damschen, G. Enskat y A.G. Vigo (comps.) Platon und Aristoteles-sub ratione veritatis. Festschrift für Wolfgang Wieland zum 70, Geburtstag, Vandenhoeck und Ruprecht, Gotinga, pp. 286-303.

Welsch, Wolfgang, 1987, Aisthesis. Grundzüge und Perspektiven der Aristotelischen Sinneslehre, Klett-Cotta, Stuttgart.

Recibido el 4 de septiembre de 2009; aceptado el 28 de septiembre de 2009. 